\title{
An insider's view of Alzheimer: cinematic portrayals of the struggle for personhood
}

\author{
By Amir COHEN-SHaLeV ${ }^{*} \mathcal{E}$ Esther-LeE MARCuS ${ }^{\dagger}$
}

\begin{abstract}
This article looks at three recent films in which a person with dementia is the principal character. These films have been chosen according to the following criteria: representing different stages of dementia (early, moderate and advanced); films where the demented is the protagonist; and films challenging the biomedical view of dementia. Two of the characters are diagnosed with Alzheimer's disease: the protagonist of Cortex (2008) is at a moderate stage, the one in Pandora's Box (2008) is diagnosed when already in advanced stage and the third, the protagonist of Old Cats (2010), while not officially diagnosed, is in early onset of dementia. While the number of dementia films has significantly increased during the past decade, only a few access the subjective world and acknowledge the personhood of people with dementia. Made outside the mainstream film industry, making elaborate use of cinematic image and metaphor, these films, each in its own particular cinematic idiom, succeed in conveying the psychological, social and spiritual realities of dementia as they are experienced from within the protagonist's psyche. While not denying the often bleak and painful aspects of dementia, these recent

* Amir Cohen-Shalev, Department of Gerontology, University of Haifa, Haifa, Israel $\dagger$ Esther-Lee Marcus, Acute Geriatric Department, Herzog Hospital, The Hebrew UniversityHadassah Medical School, Jerusalem, Israel
\end{abstract}


International Journal of Ageing and Later Life

productions go against the grain, inspiring a complex, richly nuanced picture of dementia that centres around the protagonist's stubbornly courageous struggle to forge a meaningful existence even in the direst of circumstances. These films, we believe, offer a richer and profound understating of the human aspects embedded in the phenomena of dementia.

Keywords: Alzheimer's disease, cinema, dementia, personhood.

\section{Introduction}

"People with dementia are largely invisible in most of [the Alzheimer's] literature" - this statement, made by Karen Lyman (1989: 603), is as valid today as it was almost a quarter of a century ago. Alzheimer's discourse, both cultural and academic, has consistently shifted attention away from the individual "patient" to the plight of the caregivers (Herskovits 1995), paying little attention to the experience of living with this condition (Beard 2004). Care practices, partly as a result of pervasive medicalisation of dementia, are premised on a model that denies the person with Alzheimer's an agential role in the constitution, manifestation and maintenance of personhood (Kontos 2005).

Alzheimer's disease (AD) has received considerable attention in the popular media, where a very negative and undifferentiated view of the disease has generally been presented (Beard 2004). The media have, in general, constructed a portrait of $\mathrm{AD}$ that emphasises "personal losses and interpersonal ravages .... replete with clichéd metaphors and representations in which Alzheimer's is characteristically drawn in colourfully dramatic terms that paint vividly disturbing images of a monstrous disease" (Herskovits 1995: 152, see also Behuniak 2011; Van Gorp \& Vercruysse 2012).

While mainstream cinema has recently made considerable contribution to the public visibility of Alzheimer's and other forms of dementia (Segers 2007; Van Gorp \& Vercruysse 2012; Wedding et al. 2009), these films (i.e. A Song for Martin [August \& Isaksson 2001], The Savages [Jenkins 2007] and Away from Her [Polley \& Munro 2006]) are usually more preoccupied with the selfhood of the figures surrounding the character with dementia, rather than on those suffering from it (Chivers 2011: 62; Filley 2008). 
According to Basting (2009), these films have unintentionally reinforced negative stereotypes that induce fear of dementia. Swinnen (2013: 113-114) contends that mainstream dementia films "typically render the story of a disease in progress that reaches its nadir in the time span of the narrative and use metaphors, such as darkness, to add to the story of decline. Their overall atmosphere is nostalgia for an idealized past".

We intend to rectify this omission by considering three films made outside the mainstream film industry, the first, made in France, the second, in Turkey and the third, in Chile. We thus acknowledge at the outset the different culture perspective from mainstream popular cinema these films afford. Relatively free from commercial pressures, these films explore the narrative and psychological territories left outside the reach of popular cinema. Evidently these films, which are typically low-budget, local productions, receive comparatively little exposure and are not always brought to the attention of the gerontological community. The films have been chosen according to the following criteria: representing different stages of dementia (early, moderate and advanced); films where the demented is the protagonist; and films challenging the biomedical view of dementia. The contribution of these films to re-evaluating widespread beliefs and stereotypes in the discourse of dementia is one purpose of this article. Increasing their visibility and circulation within the professional community is another.

\section{The Secret Agency of a Demented Mind: Cortex}

Cortex (Boukhrief \& Moreau 2008) is the story of an ex-policeman, who opts to protect himself from the pitfalls of dementia by moving into The Residence, a facility designed to provide for elderly patients with neurodegenerative disorders. The opening scene shows an ageing, yet well preserved man in the quiet privacy of his home, packing for some kind of trip, the nature of which remains at this point obscure. The quiet in the room (the soundtrack is minimalistic to the point of muteness) contributes to a sense of inner void, while at the same time alerting the audience to the man's concentration in the act of packing. The choice of objects, normally a standard routine, is anything but here, planting a sense of wonderment, possibly even discomfort as to the nature of the ride as well as the 
International Journal of Ageing and Later Life

particular condition of the rider to be: a Rubik's cube, a book of Sherlock Holmes adventures, and a revolver. The last object is lifted off a trash can after a brief search. The choice of objects is intriguing: the first suggests mental agility and abstract thought; the second - the joy in the mystery of problem-solving and curiosity as to human nature; and the third - the practicality of administering justice and self-defence, as well as potential violence, including possible suicide. These aspects of the human condition, as they specifically apply to $\mathrm{AD}$, are cleverly and richly investigated in the film. In the silent, understated opening scene, we are introduced to a character in some transition, whose movements are somewhat hesitant and laboured, who performs routine activities with some difficulty and whose decisions are, to some extent, unusual. It is especially significant that our pre-interpretative perceptions as viewers remain, at this point of the narrative, necessarily unresolved: we may entertain various understandings, yet these are suggestive, the picture hardly allows certainty. The certainty arrives a few moments later: having experienced doubts and hesitations, and very likely some degree of suspense, we follow the protagonist as he meets his son in the following scene. The son has come to escort the father to his destination. In accordance with the previous scene, the meeting and the ensuing ride are patently underplayed from a histrionic point of view. This flat delivery stands in contrast with the piece of information given in the sparse dialogue between father and son: "What is this disease that I have been called", asks the father, "Alzheimer's", retorts the son tersely.

The opening scenes thus create different levels of spectatorship. They establish a tone of emotional coolness, provide space for logical consideration rather than sentimental upheaval, and in their enigmatic subtlety introduce a narrative convention of a suspense story to follow. Moreover, these scenes, in their meticulous use of the language of film, help place AD as a condition-in-progress, a problem to be negotiated, not a verdict to be contained as loss. It supports an approach to this affliction as one of life's unexpected changes that have to be confronted and coped with in a cool fashion. It is presented here as a condition, not in juxtaposition with normal life, but conjoined to it. In other words, Alzheimer's is looked upon here, a-priori, as a state of mind, rather than its common perception as a form of mindlessness. 
It is an attitude that, importantly, is likely to affect viewers, and set the viewing mood in accordance with the protagonist's mission. In contrast to the majority of mainstream $\mathrm{AD}$ films, Cortex has an $\mathrm{AD}$ protagonist who is the dynamic (rather than passive) focus of both identification and dignity. Charles Boyer, the retired police detective, is not long in the residence before ominous events begin to occur - including a high number of deaths among the patients. Eschewing the notion that this may be inevitable given the ages and illnesses of the populace, Charles begins to investigate. Questions linger about whether his suspicions are valid or merely a product of the ex-cop's Alzheimer-driven paranoia. The viewer realises that the protagonist's AD identity is inseparable from his identity as a detective. In fact, the hero does not lose identity with the onset of AD; his identity becomes embedded in the new situation. He continues to live through his former identity even as $\mathrm{AD}$ gradually takes control over his consciousness. The ex-detective's decline seems to be floating in and out, leaving the viewer guessing whether he's deliberately fooling the institute's staff or simply heading swiftly towards oblivion. The institution becomes a hostile world in which the protagonist is forced to move with care, suspicion and audacity. The authorities do not mean well, and it is not clear whether staff members are working against him or simply caught up in their own petty hatreds and jealousies. Fellow travellers unexpectedly cross the protagonist's road and then mysteriously disappear. We are offered a glimpse of the world from the AD patient's point of view: pathological paranoia and normal hostile world scenarios (Shmotkin 2005) keep alternating, adding to an already fragile consciousness. At times, despair has the upper hand, for example, when Boyer becomes convinced that he is haunted by his own demented ghosts. It is easier to play up to the expectations of the "healthy" world outside. At the end, though, perseverance wins the day, and the AD-stricken ex-detective is rewarded with recognition of his intellectual achievement. The victory is temporary, no doubt, but a moment of satisfaction and pride makes all the difference between unconditional defeat and combative fulfilment. "What was my code name back in the department", he asks his son at the end; "Cortex", comes the answer. The seat of intelligence, identity and creativity has won its last battle.

There is a moral issue involved here with respect to the notion of verdict. Many of the mainstream AD films, following and reflecting a widely held 
International Journal of Ageing and Later Life

public attitude, implicitly ritualise $\mathrm{AD}$ as a thinly disguised metaphor for an imminent death-verdict, thus underplaying its chronic nature, while exaggerating its terminality. When Boyer, Cortex's protagonist-patient, leaves the privacy of his world and enters the institute, he steps into the public sphere and has to confront its beliefs and prejudices. The institute's socio-cultural universe stands as a symbolic parallel to contemporary society at large, while the narrative convention of a thriller accentuates and magnifies the dynamics of exclusion, even persecution of the demented person by a threatened establishment. When Boyer sets out to investigate the mysterious disappearance of fellow patients, he relies on unfailing professional knowledge and a stubborn sense of agency. He makes optimal use of these capacities to act in subversion of the system. His paranoia, then, rather than being conveniently stigmatised as a medical symptom characteristic of dementia, is a justified, patently sane response to an obtuse, indifferent and evil social system. Nicolas Boukhrief, the film's director, challenges well-entrenched stereotypes concerning the depiction of $\mathrm{AD}$ in the film. First, this film focuses exclusively on the AD patient (rather than on his relatives or caretakers, the protagonist's son is important, but only as a background support). Second, the cognitive as well as psychological intricacies involved in AD constitute the focus of inquiry, as they are magnified and treated in detail - treated as processes, not bypassed as symptoms. The medical realities of $\mathrm{AD}$ are fully contextualised in the sense that they are attached to feelings and rationalised in action. Cortex uses $\mathrm{AD}$ as a narrative device, cleverly blurring reality and imagination as the viewer is gradually led to believe that the whole thing may be taking place only in the confused mind of the patient/protagonist, while being positively disillusioned again at the very end. This double disillusionment lends a special significance to the film not credence in the sense of medical or psychological credibility, but what we might call metaphorical credibility. The AD victim's desperate efforts to combat his condition, to fight what seems to be a lost battle and arrive at some success, although modest and probably short-lived, is a triumph of some consequence, and a metaphor for strength and stamina in the face of a sealed fate. It is a reminder of a famous line from Alain Resnais' Providence (Resnais \& Mercer 1977), where Clive Langham, the dying and ailing writer, takes his leave from his family with the words "Nothing is 
written", an enigmatic phrase, possibly meaning nothing is predetermined, and there is a freedom of choice even in the most constricting of circumstances.

\section{The Horizontal Turned Vertical: Pandora's Box}

Circumstances are certainly worse for the Alzheimer's character in the next film we discuss here. Family, rather than biology, is the battleground of the Alzheimer's protagonist in Pandora's Box by Turkish director Yesim Ustaoğlu and Kaygusuz (2008). This film puts AD within familial contexts (Dönmez-Colin 2010). In a similar manner to Cortex, Pandora's Box's opening scene, prior to the screening of the credits, is of prime importance to the viewing experience, and, by extension, to the picture of $\mathrm{AD}$ it promotes. A long, very slow pan shot of a green mountain appears on the screen, basking in bright morning light, setting a mood of pensive calm and quiet natural beauty, punctuated by unobtrusive chirping of birds. The shot continues, capturing a country house, stopping at a second one. The camera at this point cuts to what seems to be the interior of this second house, where an old, stooped peasant woman, Nusret, seen from behind, is walking slowly towards the balcony. Next, the old woman is seen standing on the balcony, holding a white bag with red acorns, spreading them on a tray. Her gaze wanders for a moment, and then, with no apparent reason or purpose, her look turns into an intense stare of uncertain emotional quality, partly horror, partly determination, confused and sharp at the same time, with no apparent focus in the real world. There is a suggestion of some kind of inner turmoil in her stare, but for the viewer the reason remains opaque, immanently unclear. This gaze - focused inwards rather than outwards - is troubled to the point of panic, yet very contained all the same.

The camera cuts from the woman's gaze to the bag of what seems to be acorns, or some other kind of nuts, that now appears left open, catching the acorns spreading on the floor of the balcony, as the old woman turns abruptly away from the balcony and moves inside the house. It is left for the viewers to speculate on the nature of the old woman's behaviour and possible motive. There is no dialogue at this point to support a possible explanation, no narrative clue in the scene and no musical score to help define a certain emotion or mood. Whatever pointers are given, they are 
International Journal of Ageing and Later Life

highly suggestive, bounded by prior knowledge of rustic life. Admittedly, the prior knowledge that the film has $\mathrm{AD}$ for its subject may have informed our own expectations and prompted a reading of the highly evocative yet ambiguous visual details in the scene as dementia related. The acorns spilling through a torn bag, for one, can possibly, though not exclusively, be taken as a visual manifestation of a consciousness falling apart. Both themes, mental breakdown and unlocking familial troubled relations, are given their thematic due later in the film. The old woman's stare introduces an additional difficulty, in that we can only assume the gaze is directed towards the mountain, and the consecutive arrangement of the shots (mountain, then frontal close-up of the woman's gaze) suggests an intense, unspoken dialogue between a non-human object (mountain) and a human subject (the woman's face). What the viewer is left with at this point is a vague, troublesome intensity. Still, as minimal and intrinsically equivocal these pointers may be, their potential suggestiveness is quite impressive: several viewers have responded to the elusive reverse-shot juxtaposition of the mountain and the old woman's sudden turn with the idea of an intuitive anticipation of a scene towards the end of the film, where she admits to hearing voices telling her to go to the mountain.

The upsetting quality of this scene is crucial for the comprehension of the film in its entirety, preparing the audience for the inner journey into a complicated mental terrain. Within a few scenes, the disturbingly enigmatic introductory scene will be taken apart and resolved, but not before we will have been taken to very different territories. This opening scene reminded us of another one, well known to film aficionados and scholars, the dream scene in Ingmar Bergman's classic 1957 film Wild Strawberries, where the old protagonist, Dr. Isak Borg, wakes up in the middle of the night from a bewildering and strange dream, goes to the window, looks out, and then turns the other way with a body language that transmits determination, obviously related to the experience of the dream, but in ways that are yet unclear (Bergman 1957). That sense of vague but powerful determination is also shared by the old woman in Pandora's Box when, following her strangely concentrated stare at the mountain, she decisively turns away, as if driven by a sudden change of mind. 
The sequence immediately following the credits comprises short scenes depicting a number of characters moving about in a defined environmental context, but still telling us very little about their identities. First, in the sequence is a picture of a seaport at dawn, very grey, its flat horizontality standing out in strict juxtaposition to the vertical mountainous scenery of the opening scene. It takes a few seconds to spot a young man, Murat, lying on the stone deck of the harbour, woken up by the sound of a cellular phone ringing. Listening for a few seconds, he does not reply and puts the mobile phone back in his coat pocket. The scene then cuts to the bedroom of an urban apartment, where a woman, sitting beside a bed where a man is sleeping, shows signs of frustration as her calls are not being returned.

The way the narrative unfolds is significant in that it renders the viewer responsible for putting together these bits and pieces, which are disconnected in terms of place and narrative logic, yet are connected by an underlying emotional logic. They belong to their environment, but at the same time they are also alienated from it. These scenes are minimalistic, patently visual, deliberately doing away with either dialogue or soundtrack, creating an overall effect of barren distress, blocked communication and general estrangement. It is a puzzle of disconnectedness. The structure of the introductory scenes is deliberately fragmented, fallen apart as it were, the way the acorns in the old woman's sack spread apart, the way her consciousness is being destroyed by AD.

About a quarter of an hour into the film, a story seems to be forming. The old woman of the first scene had disappeared from her village somewhere in the mountains above the Black Sea in contemporary Turkey. Her three adult children drive up from the city to find her. There is also a grandson, Murat (the young man from the opening harbour scene), a student whose relationship with his parents is in deep crisis. Crisis is an on-going reality in the lives of the old woman's children. The older daughter is unable to maintain a marital relationship with a husband who loves her, the younger daughter is having a frustrating affair with a married man, the young son is leading a down-and-out-life in a poor, rundown neighbourhood and the grandson, Murat, who had never met his grandmother, is a school dropout and a drifter.

Into this drab family situation enters the old, Alzheimer's-stricken woman. To her family, she is "acting strangely". At first they do not make 
International Journal of Ageing and Later Life

the medical connection, probably because she had been a stranger for them for many years, and vice versa. Bits of information scattered throughout the film depict a grim picture of desertion and even hatred. The father had apparently left the household for a younger woman, and there's barely a mention of him. There is not only a mixture of bitterness, envy and grudge but also closeness, intimacy and occasionally warmth and care among the children, little of which shows in their attitude to their mother.

The medical establishment plays a minor role in this film. The old woman is diagnosed (through the usual procedures and tests), and the doctors are sympathetic to the family's helplessness and suffering, but that is all. At the point where grandma is inevitably institutionalised, her grandson takes it upon himself to take her to "her mountain", the mountain that was the focus of her gaze in the first scene, the only constant mental feature that she can hold intact in a consciousness that is falling apart.

The critical role the grandson will come to play had been carefully prepared from the very beginning. From the start, he seems to have a deep affinity with the old woman who is, like himself, a lost soul, thrown out of normative existence into a whirlwind of estrangement, distress and terrible loneliness. He sees her medical condition, not as a clinical symptom, but as some kind of extension of his own way of being in the world. A "standard" feature employed in AD films to signify the advanced stage of $\mathrm{AD}$ is incontinence in public (e.g. A Song for Martin). When Grandma urinates on the carpet in his mother's living room, Murat, his aunt and uncle respond with uncontrolled laughter. A comment later on sheds some light on this presumably improper behaviour: "I'd urinate on that carpet too" Murat tells his uncle, a wanderer himself, with whom he can comfortably confide. When he is robbed, and then almost killed by his robber, the experience of imminent death also informs Murat's bond with the old woman.

The moments these two lost souls spend together; the mute, natural warmth that infuses their time together, literally light up the screen as they break bread on the deck of a cruise vessel on the Bosporus. Indeed, the only sunlit scenes in the film take place when they are together. The second sunlit scene is also the closing one in the film, another richly 
metaphorical scene. Murat, Nusret's grandson, has assumed the role of her only caretaker. He grants her wish ("take me to my mountain") to return to her village. The moment the decision is taken is significantly tied up, in pure cinematic terms, to the recurring symbolic topography of the miseen-scene. The moment follows the institutionalisation of Nusret by her children, as they realise they are incapable, in their miserable helplessness, of caring for her. Left alone, she is seen wandering in the institute's fenced inner yard, very much resembling a prison courtyard. The camera's point of view is that of Murat watching from above, positioned, as it were, at the top of the brick wall surrounding the yard. Next, grandmother and grandson are seen together in the midst of a crowded city street. The act of abduction is made clear in hindsight: the youngster who had been drawn close to his Alzheimer's-stricken grandmother took action in going over the fence, both literally and metaphorically, down into the lower yard, and has lifted the old woman up into the street, and then through Istanbul's bustling confusion, up to the mountain.

The scenes back in the mountain village form an unusual, almost uncanny mixture of tranquillity, inner peace and imminent departure. It is an idyllic picture of grace that at the same time acknowledges the bitter and distressing reality of $\mathrm{AD}$ for both bearer and caregiver.

The mountain is a dominant presence throughout the film. It provides the framework for the dramatic development, first the yearning to be borne out of a dreadful situation, namely the disease, then as a getaway from a devastating estrangement of a hopeless and helpless social environment (the Istanbul scenes) and finally as a salvation-in-death, as Nusret asks Murat to let her disappear again into the mountain before utter forgetfulness takes over ("let me go to my mountain, before I forget that too") - her last, telling words in the film, as well as her ultimate, lucid autonomous decision.

The last scene, in Nusret's country home, comes full circle to the first, but with a change of direction that makes a crucial difference that produces a poetic, richly metaphorical ending. Murat wakes up to a perfectly clear day, the very clarity at the exact same location of the opening shot, only to find out that Nusret has gone. Looking out he sees her figure down in the valley, on the path leading to the heights. It is another moment of intense concentrated conflict, as his face and hands 
International Journal of Ageing and Later Life

twitch in an effort to contain the pain. His excruciatingly painful dilemma is laid bare in a close-up shot. It is his mute promise to help her-against the impulse to rescue her-and the obvious knowledge that having taken action to rescue Nusret from the mental institute meant he will have to take another decision, this time a decision not to take action, but to let her die and to respect her way of dying. Whereas his decision to "abduct" Nusret had been based on compassionate empathy, having also a reversible contingency component in the background (like leaving home) this time it is an ethical choice, forcing a different, adult responsibility, of the sort he had desperately been putting off prior to the events brought about by the story. It is at this junction that Pandora's Box calls for a differentiated definition of care, in the immediate context of $\mathrm{AD}$, possibly for a more generalised human context, where, drawing on Erikson's typically adult stage of ego-development, "caring for" in such particular circumstances takes priority over "taking care of". That is, attending to the call of subjective dignity takes precedence over that of continued communal care.

The end of the film again addresses this dilemma in the visual vocabulary and spatial architecture it has adopted from the start. Leaving Murat's conflicted, agonised face, the camera tilts up slowly, gently drawing the direction of the old woman's final destination, "her" mountain. The vertical movement of the camera is a perfect recapitulation and completion of its horizontal movement in the opening shots. Both opening and closing shots are slow, their pace calling for our contemplation. While sideways panning invites an attitude of detailed investigation, a slow upward shot directs us in the direction of contemplating a transformation. Still, here as well, the ending is highly ambiguous: lifting the viewer's gaze up is not necessarily an uplifting experience, far from the proverbial "spiritual redemption". The two mountain shots are indeed suggestively complementary, but they are not identical. The earlier is more distant, while in the latter, the mountain is upstaged in a close-up shot, suggesting that the old lady may already be in it. The metaphor of reaching the sky, connoting optimism and redemption, lies outside the teleological boundaries and hard-headed, unsentimental cinematic credo of Pandora's Box.

"Unsentimental" is an apt descriptor of the third and last film we review here. 


\section{Onset in Slow Motion: Old Cats}

Old Cats (Gatos Viejos, Chile, [Peirano \& Silva 2010]) is a chamber film, a tough, tightly structured domestic drama with a twist: the emotionally charged drama of mother-daughter relationship is explored against the onset of dementia (Rich 2011). Faced with filial anger, the extent of which she had not fathomed, Isidora (Isi), in her late eighties, and experiencing devastating symptoms of cognitive as well as physical decline, makes a valiant and painful effort to resolve a lifelong crisis.

An outstanding feature of this film is its temporal, as well as spatial, constraints which create a strong sense of immediacy and urgency, thus reflecting the subjective situation of the protagonist. The story takes place over less than 1 day, the first scene in late morning, the second in late afternoon. Other than one time lapse that is omitted for the sake of narrative continuity, story time and chronology are identical. In other words, Old Cats unfolds in real time. As for location, the story unfolds in one enclosure, a flat on the eighth floor of an apartment building in Santiago de Chile, with one exception of a scene taking place outside the building in the street below. Not only is the setting sparse, but, no less important, background information about the characters is so slim that the only way the viewer can make their acquaintance and gain knowledge of their character is on the basis of their immediate actions; no reference is made to their history, or to their former or present occupations. What is made to matter is the immediate moment. This is the reason that when the outside world and other times make a brief appearance, their dramatic and psychological importance are magnified. This highly minimalistic setting provides the bare physical context, mere scaffolding upon which another story leans, a story that takes place at a sphere away from and beyond the physical reality of place and time. While confined to the "here and now", the story of Old Cats tells a parallel story, where both place (here) and time (now) are collapsing from within, through a consciousness that is in the process of disorientation, falling apart as a result of dementia. Thus, narrowing down of physical reality of conventional time and place parallels the shrinking dimensions of the mental space brought about by this condition.

It also means that the story of the film, while involving various characters and a central dramatic conflict, is experienced in the present tense of the central character's consciousness, as she oscillates between 
being in "sane" stability, being in the here and now, and the fluid evanescence of "other" temporal as well as spatial modes. Isidora's inner story throughout the film revolves around these fluctuating polarities of a consciousness, at times stable and lucid, and then unexpectedly wavering towards forgetful oblivion, between presence of mind and the loss of mind, threatening to take over by surprise at any moment.

Isidora's mental struggle between lucidity and opaqueness from the outset is echoed in the imagery and symbolic universe of the film. The opening image is of a statue of a horse, silhouetted against the light coming through the window of the apartment she shares with Enrique, her husband and caregiver. The horse is in a position of arrested movement, its two front legs caught in the air, as it were, and, as such, standing for an object at the same time animated and inanimate, an early symbolic anticipation of the protagonist's liminal mental condition. Situated among various other animal statues, the image of frozen life is contrasted with the two cats of the title, gently moving through their adoptive territory, demanding food and attention, soon to be echoed in the character of Rosario, Isi's daughter.

Moving into the couple's bedroom, the camera shows Enrique reading in bed, while Isi is sleeping - a medium shot, squarely framed routine stability, yet short-lived. The next shot gets uncomfortably close to Isi's old and wrinkled face, her eyes opening. They are frightened, restlessly scanning, yet essentially unseeing with unfocused gaze, her surroundings. Facing the camera at close range, this too-long-for comfort (35 seconds) shot established a theme of non-recognition. She blurts out a cry: "I don't want to", then impatiently explains it away, in response to Enrique's question, as a bad dream.

A phone ring cuts the silence, instigating a panic-laden thought from Isidora fearing that an old friend about to make a visit has died. But Enrique, wryly informs her it is her daughter Rosario, which he finds worse. Rosario's aggressive, demanding, highly stressed manner, already evident through her hyperventilated speech, and the visit she imposes on her reluctant mother, has Isidora "on her feet" again. Preparing for the unwanted visit further exposes her deep mental distress and precarious hold on reality. A beautiful, extreme close-up shot of her eyes looking up at the running water in the shower, holding out her hand, feeling the water 
running, conveys a deeply sentient person, and also establishes the image of running water as central to her threatened being, a metaphor that will gain more meaning later in the story.

As Isi goes out the door for the purpose of getting food, she is held back by a stuck elevator (another image of halted movement, linked physically to her walking difficulty caused by a hip problem, as well as symbolically to the severed movement of her mind). Enrique's efforts to comfort her ("it's not you, it's your hips") fail to dispel a deep sense of despair. Left alone, as Enrique has to go out instead, there are a few moments of absence. This is followed up by incoherent speech, and Isa pouring the spilled contents of a drawer on the bed. Because she had forgotten to turn off the bathroom faucet, the flat flooded - another appearance, this time ominous and threatening, of running water. Before she manages to stop the flood, she has a moment of utter confusion and panic, about which she later tells Enrique: "I got lost Enrique! Everything is flooded! There's water everywhere! I lost track of time! I do not know what I was thinking!"

An image of the table prepared for the visit marks the transition to the afternoon and to the visit of Rosario. Into the darkly lit flat bursts an abrasive, cantankerous, deeply troubled woman who has been harbouring bitter resentments of her mother.

Rosario's neurotic desperation is soon revealed as a thin disguise to a profound hurt. There are hints of a history of financial abuse on Rosario's part towards her mother, money she has irresponsibly spent on bizarre enterprises that had come to naught. This time she is selling homemade, organic soaps she and her companion had just brought back from Peru, and she needs to get a lease on Isi's apartment. The old woman's signature becomes a metonym for autonomous identity and agency. The exchange takes place against the constant threat of exposing Isi's mental problems, moments of "checking out" that, despite Enrique's resourceful camouflage manoeuvres, she finds progressively difficult to hide.

Rosario, immersed in her feeling of maternal neglect, attributes her mother's occasional incoherencies to her cold, ungiving nature.

"I wish she was senile. That'd make things easier. Don't let her fool you, she's hard, cold, selfish. She'll die that way ... she never loved me". 
International Journal of Ageing and Later Life

Rosario's pressing emotional needs do not allow her to perceive her mother's condition. Enrique sees this as selfish lack of sensitivity on her part, yet, ironically, by refusing to recognise Isi's medical condition, Rosario perceives her mother as an active agent, a complete self, though a faulted one. This lack of perception allows Isi to maintain her autonomy, and finally make a major decision. In other words, by perceiving her mother as independent, Rosario in fact contributes to that independence. In contrast, Enrique perceives Isi as no longer independent; thus, he is willing to make allowances.

In the midst of this tense dialogue, there is a particularly pertinent incident in which Isi goes out to the balcony and looking ahead sees on a cliff opposite the building a group of people dressed in bee-like costumes, gently floating in slow motion on the rocky slopes. Isi is entranced by this mysterious apparition. The image is clearly dream-like, and, taking the point of view of Isidora, viewers of the film are made to wonder whether this may be a vision created by Isi's peculiar state of consciousness caused by the dementia. Ultimately, the viewers, like Isidora, become disenchanted when they realise that these aerial figures are real enough, dressed for the purpose of making a commercial. It is a moment of magic, a sweet illusion, and for this brief moment Isidora is carried away into the realm of pure imagination. Back into the reality of a bitter familial rupture, she demands to be left alone with Rosario, against Enrique's protest:

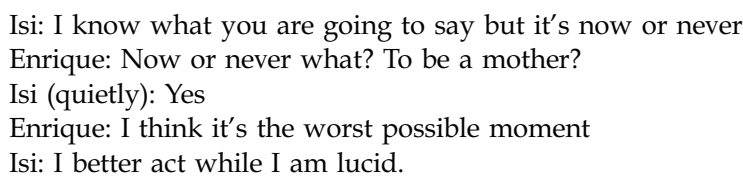

Fully lucid, face to face with Rosario, Isi is confronted with her maternal failure. "Tell me one memory of us together" asks the deprived Rosario in anguish, and Isi is mute. It is clear this is not a case of dementia-related loss of memory, but an admission that the kind of memory Rosario is asking of her mother had never been there. Intent to conceal her mental deterioration, Isi cannot fall back on the illness to defend herself, but it is also clear she would not even if she could. 
Rosario's silence lays bare the true nature of her greed:

You never loved me, you are ashamed of me, that's why I take your money.

When Rosario discovers a note from Enrique, hidden in her mother's palm, warning her against signing the lease, she slaps her mother on the face and walks out of the apartment. This turns out to be a moment of epiphany: it is as though parental failure literally hits Isi hard in the face. The bare physical expression of filial hatred deeply unsettles the old woman even as she begins a retreat towards mental oblivion. It may be the confrontation with another loss that shakes her profoundly. Now, at last, despite walking difficulty and an out-of-order elevator, Isi descends eight floors of steps, with apparent tremendous effort.

Until this moment in the story, the point of view has shifted back and forth between Isi's subjective state and an outside, more objective perspective of the filmmakers. Then Isi begins her trip down the stairs (a momentous decision, considering that when in the morning she learned that the elevator was not working, she immediately returned to the flat). And, for the entire duration of the next sequence, we experience everything through her eyes. Interestingly, while the initial impetus to step outside was to follow Rosario, who had left the apartment in anger and sat down on the stairs one floor below, now, as in the opening hallucinatory "dream" scene, the point of view taken is predominately Isi's own.

The encounter with the world outside her flat accesses two images previously introduced in the story, and closely associated with Isi's internal world, the floating bees, now at close range, and also running water, now in the form of a fountain cascade, into which she obliviously wanders in bewitched, transformed childlike wonderment. This powerful image of falling water symbolically coalesces from the different, contradictory meanings it has for the character of Isi into a complex picture of her mind, the mind of a person struggling with mental deterioration: clarity, purity, movement, transparency and rejuvenation, and, at the same time, drowning, flooding, suffocation and death.

For the now over-wrought Isi, this "getting lost" encounter is, paradoxically, a breakdown moment and an awakening experience of 
International Journal of Ageing and Later Life

self-revelation. As Rosario rushes to pull her mother out of the pool, there is a brief moment of mother-daughter physical bonding, where the exhausted, soaked old woman asks her daughter's forgiveness, sharing with her the terror of her condition:

Forgive me. I'm losing my mind. I'm going crazy ...

Carried back to the flat, she turns to Rosario:

I have a memory! We were crossing a river, you up to your knees, the rest of the kids were on the other side, you were so small. You know what I did, I let go of you, and you made it.

The bewildered Rosario says she does not remember that, and she is right. A moment later Isi confesses to Enrique:

I realized that memory I told Rosario wasn't about her. That happened to me when I was a girl ... not her. I'm not here anymore.

The strange and unexpected displacement of memory surprises the viewer as well as the one who remembers: memory here functions differently from usual memory: it is not reminiscing, nor is it nostalgia, not even a conscious recollection made for the purpose of preserving identity in the face of loss. The old woman, conscious of the fact she is about to "lose her mind", recruits, then transforms, a dim recollection from her own childhood (instigated, we may assume, by her own "crossing a river" a moment earlier). This is a "white lie", a creative use of memory and imagination. To borrow a phrase from Basting (2009: 48), "present and past overwrite each other". The conflation of remote and recent memory, which normally would constitute a disruption of a normal sense of time, is here made to serve a purpose in binding mother and daughter together, and for the old woman aware of sliding to dementia, an opportunity never to be repeated to salvage lost motherhood and by that achieve a meaningful closure to a lifelong conflict. Encroaching dementia has inspired a restructuring of priorities, emotional growth and, for once, a connectedness that would have not been possible in the so-called "healthy" state prior to its onset. 
In her moment of transformation, Isi gives up her apartment, deciding, against Enrique's better judgement, to sign the lease for Rosario. "I' $m$ not here anymore", she says, but the last shot of her suggests that at this moment, she is very much here, even as her being is an altered one. Seated calmly, her expression bespeaks of deep sadness, but also of a self-fulfilled relief. She has lost the lease of her apartment, but has gained a new lease on her disrupted relationship with Rosario. The signature, rather than an act of foreclosure, becomes a symbolic act of will and a signifier of advocacy.

\section{Conclusion}

The view that Illness fosters transformations, sometimes drastic, of identity (Beard 2004: 417), and that sense of self must be actively reconstructed (Cohen-Mansfield et al. 2000) is powerfully illustrated, with added artistic credence, in the last episode of Old Cats, discussed above. The climactic scene perfectly resonates with the late Tom Kitwood's eloquent words:

\footnotetext{
In dementia many aspects of the psyche that had, for a long time, been individual and 'internal', are again made over to the interpersonal milieu. Memory may have faded, but something of the past is known; identity remains intact, because others hold it in place; thoughts may have disappeared, but there are still interpersonal processes; feelings are expressed and meet a validating response; and if there is a spirituality, it will most likely be of the kind that Buber describes, where the divine is encountered in the depth of I-Thou relating.
}

(Kitwood 1997: 69)

Kitwood's seminal work on personhood and person-centred care clearly challenged the biomedical, capacity-based view of the loss of personhood at the onset and advance of dementia. The view of the self remaining throughout the progression of dementia is becoming far more established (Baldwin et al. 2007: 174).

Popular cinema both reflects and enhances cultural position and stigma (Behuniak 2011). AD has received considerable attention in the popular media, and the mainstream motion picture industry is no exception (Chivers 2011) in promoting a very negative and undifferentiated view of the disease (Kontos 2005). Until recently, the dominant story told about 
International Journal of Ageing and Later Life

people with memory loss is one where their speech is deemed meaningless, their memory defected and their sense of self lost (Beard 2004: 417). More recently, researchers have begun to challenge the view that dementia inevitably leads to loss of self (Sabat \& Collins 1999). There is a "significant shift from the focus on tragic decline" in the stories we tell ourselves about dementia (Basting 2009: 48). This shift challenges the notion that people who have dementia, Alzheimer's and other types, become hollow shells, without a trace of personhood left in them.

Taken together, each of the three films discussed here, one made in France, the second in Turkey and the third in Chile, in its own particular way, offers a different picture of dementia, whether of AD type or other types, in that they insist on getting under the symptom-ridden medical reality of the disease and into the subjective mental territory and aspects of personhood scarcely touched upon in mainstream culture. Common to these films is the portrayal of the AD-stricken protagonist, two old women and a middle-aged man, as fully sentient, complex and complete human beings, despite, sometimes because of, their cognitive impairment. These individuals, one in already advanced stage of the disease (Nusret, Pandora's Box), moderate (Boyer, Cortex) and early (Isidora, Old Cats) possess a strong sense of identity and purpose, struggling to retain control over their situation and a sense, paradoxically enhanced, of inner freedom and choice. Determined to construct meaningful lives despite the challenges, these fictional portrayals provide a timely cultural corrective to the clichéd metaphors and representations in which dementia is characteristically drawn in colourful and disturbing images (Herskovits 1995: 152), images based on, and that in turn reinforce, widespread fear.

This fear, though quite understandably natural, has perpetuated the view that persons who have $\mathrm{AD}$ are more severely impaired than they actually are, and that instead of being seen as unique, diverse individuals, they are likely to be lumped together and seen only in relation to a category - late-stage $\mathrm{AD}$. Late-stage $\mathrm{AD}$ is not always seen accurately either; research evidence suggests (Lyman 1989; Sabat 2001) that even those who are in the late stage are not always as impaired as they are assumed to be, a point poignantly illustrated in the character of Nusret in Pandora's Box. 
Yet, as a collaborator in the struggle of cultural and humanistic gerontology to humanise dementia, films such as those discussed here can provide more than mere illustration. They operate like silent partners, going deeper than words. In other words, these films, primarily, if not exclusively, use as their major means of expression those very skills that remain fully active in the lives of people with dementia, their powers of suggestion working through visual metaphor and intuitive thinking. The dialogue between the concrete, actual materials the films use is analogous to the dialogue that persons with Alzheimer's or dementia maintain with their physical and social environment. Watching these films allows the viewers to transcend the barrier of language. The mountain for Nusret is a living entity, the essence of which she communicates to her grandson, who, through a naively unbiased, yet unspoiled cultural attitude, is intuitively able to decode it, and then act upon this intuitive understanding. Recognising a hermetic environment of a medical institute as a metaphor for a society hostile to people with dementia is not a piecemeal analytical process but a holistically immediate one. The dialogue with the narrative and characters in these films, during viewing and in retrospect, is mediated by the singular language of the film. It is worth noting in this respect, that although spoken dialogue plays an indispensable role in these productions, the scenes crucial to penetrating the inner world of the protagonists (i.e. the opening and sequences of Pandora's Box, the 35second shot of Isidora's "dream" at the beginning of Old Cats, Boyer's preparation for hospitalisation in Cortex) have no spoken dialogue or background score, but are purely visual, as well as kinetic. The camera patiently explores their mind's work with slow-moving shots, projecting palatable inner space where pensive, wistful deliberation alternates with anxiety. In the context of media representations of dementia, these scenes stand for more than skilled cinematic artistry on the part of the filmmakers (which apparently they are, making lasting moving pictures imprinted in our mind), but more importantly a means of closely simulating the subjective experience of dementia. By facilitating identification with the protagonist affected by the disease, the movies create a change of attitude in the viewer. In shifting the expressive centre of aesthetic gravity from abstract linguistic cognition to the figurative, tangible expressive modality of the moving picture, these films stand to encourage a deeply felt 
International Journal of Ageing and Later Life

understanding of the human aspects embedded in the phenomena of dementia.

\section{Corresponding Author}

Esther-Lee Marcus, Acute Geriatric Department, Herzog Hospital, POB 3900, Jerusalem 91035, Israel. Email: gerontology.israel@gmail.com

\section{References}

August, B. (Director/Writer), \& Isaksson U. (Writer). (2001). A Song for Martin. [Motion Picture]. Sweden: Film i Väst [Swedish, English Subtitles].

Baldwin, C., Capstick, A., Phinney, A., Purves, B., O'Connor, D., Chaudhury, C. \& Bartlett, R. (2007). Personhood. Critical commentary. In C. Baldwin \& A. Capstick (eds.), Tom Kitwood on Dementia: A Reader and Critical Commentary (pp. 173-187). Maidenhead, UK: Open University Press.

Basting, A. D. (2009). Forget Memory: Creating Better Lives for People with Dementia. Baltimore, MD: Johns Hopkins University Press.

Beard, R. L. (2004). In their voices: Identity preservation and experiences of Alzheimer's disease. Journal of Aging Studies 18(4): 415-428.

Behuniak, S. M. (2011). The living dead? The construction of people with Alzheimer's disease as zombies. Aging and Society 31(1): 70-92.

Bergman, I. (Writer/Director). (1957). Wild Strawberries. [Motion Picture]. Sweden: Svensk Filmindustri. [Swedish, English Subtitiles].

Boukhrief, N. (Writer/Director), \& Moreau, F. (Writer). (2008). Cortex. [Motion Picture]. France: Les Films du Worso [French, English Subtitles].

Chivers, S. (2011). The Silvering Screen: Old Age and Disability in Cinema. Toronto: University of Toronto Press.

Cohen-Mansfield, J., Golander, H. \& Arnheim, G. (2000). Self-Identity in older persons suffering from dementia: Preliminary results. Social Science and Medicine 51(3): 381-394.

Dönmez-Colin, G. (2010). Women in Turkish cinema: Their presence and absence as images and as image-makers. Third Text 24(1): 91-105. 
Filley, C. M. (2008). Caregivers take center stage in "The Savages". The Savages directed by Tamara Jenkins. Searchlight Pictures 2007. Neurology Today 8(3): 20.

Herskovits, E. (1995). Struggling over subjectivity: Debates about the "self" and Alzheimer's disease. Medical Anthropology Quarterly New Series 9(2): 146-164.

Jenkins, T. (Writer/Director). (2007). The Savages. [Motion Picture]. USA: Fox Searchlight Pictures.

Kitwood, T. (1997). Dementia Reconsidered: The Person Comes First. Buckingham, UK: Open University Press.

Kontos, P. C. (2005). Embodied selfhood in Alzheimer's disease: Rethinking person-centered care. Dementia 4(4): 553-570.

Lyman, K. A. (1989). Bringing the social back in: A critique of the biomedicalization of dementia. The Gerontologist 29(5): 597-605.

Peirano, P. (Writer/Director), \& Silva, S. (Director). (2010). Old Cats. [Motion Picture]. Chile: Elephant Eye Films [Spanish, English Subtitles].

Polley, S. (Writer/Director), \& Munro, A. (Writer). (2006). Away From Her. [Motion Picture]. Canada: Film Farm.

Resnais, A. (Director), \& Mercer, D. (Writer). (1977). Providence. [Motion Picture]. France: Action Films.

Rich, B. R. (2011). Sundance notebook. Park City remix. Film Quarterly 64(3): $62-65$.

Sabat, S. R. (2001). The Experience of Alzheimer's Disease: Life through a Tangled Veil. Oxford: Blackwell.

Sabat, S. R. \& Collins, M. (1999). Intact social, cognitive ability and selfhood: A case study of Alzheimer's disease. American Journal of Alzheimer's Disease and Other Dementias 14(1): 11-19.

Segers, K. (2007). Degenerative dementias and their medical care in the movies. Alzheimer Disease \& Associated Disorders 21(1): $55-59$

Shmotkin, D. (2005). Happiness in the face of adversity: Reformulating the dynamic and modular bases of subjective well-being. Review of General Psychology 9(4): 291-325.

Swinnen, A. (2013). Dementia in documentary film: Mum by Adelheid Roosen. The Gerontologist 53(1): 113-122. 
International Journal of Ageing and Later Life

Ustaoğlu, Y. (Director), \& Kaygusuz, S. (Writer). (2008). Pandora's Box. [Motion Picture]. Turkey: Ustaoğlu Film Yapim [Turkish, English Subtitles].

Van Gorp, B. \& Vercruysse, T. (2012). Frames and counter-frames meaning to dementia: A framing analysis of media content. Social Science $\mathcal{E}$ Medicine 74(8): 1274-1281.

Wedding, D., Boyd, M. A. \& Niemiec, R. M. (2009). Movies and Mental Illness 3. Using Films to Understand Psychopathology (3rd ed.). Cambridge, MA: Hogrefe. 